\title{
Is Deprescribing Swimming Against the Tide?
}

\author{
Sarab Burbank, BS \\ Rush Medical College, Rush University Medical Center, Chicago, Illinois
}

$\mathrm{T}$ he Annals of Family Medicine encourages readers to develop a learning community to improve health care and health through enhanced primary care. Participate by conducting a RADICAL journal club. RADICAL stands for Read, Ask, Discuss, Inquire, Collaborate, Act, and Learn. We encourage diverse participants to thinking critically about important issues affecting primary care and act on those discussions. ${ }^{1}$

\section{HOW IT WORKS}

In each issue, the Annals selects an article and provides discussion tips and questions. Take a RADICAL approach to these materials and post a summary of your conversation in our online discussion. (Open the article and click on "TRACK Discussion/ Submit a comment.") Discussion questions and information are online at: http://www.AnnFamMed.org/site/AJC/.

\section{CURRENT SELECTION}

\section{Article for Discussion}

Wallis KA, Andrews A, Henderson M. Swimming against the tide: primary care physicians' views on deprescribing in everyday practice. Ann Fam Med. 2017;15:341-346.

\section{Discussion Tips}

Deprescribing, the practice of tapering and discontinuing unnecessary medications, is a task that often falls to primary care physicians. This study uses qualitative research methods to explore physicians' views on deprescribing in elderly patients, a population especially at risk for polypharmacy. The article provides an opportunity to discuss the art of deprescribing and to initiate a conversation about personal, cultural, and organizational barriers to this important component of patient safety.

\section{Discussion Questions}

1. What question is asked by this study and why does it matter?

2. How does this study advance beyond previous research and clinical practice on this topic?

\section{JOIN US FOR TWITTER JOURNAL CLUB}

July 30, 2017, 7:00 pm EDT/11pm GMT, @AnnFamMed or \#AJC. This moderated chat will pose questions about the article at regular intervals.

3. How strong is the study design for answering the question?

4. To what degree can the findings be accounted for by the following:

a. How participating physicians were selected?

(Did the authors achieve saturation? That is, did they sample until the point at which no new information was obtained from further sampling?)

b. How the data were collected?

c. Risk of bias using the snowball technique?

d. Chance?

e. How the findings were analyzed and interpreted?

5. What are the main study findings?

6. What barriers to deprescribing can you identify in your practice? What incentives can you identify?

7. How comparable is the study sample to your practice? What is your judgment about the transferability of findings to your setting?

8. What contextual factors are important for interpreting the findings?

9. How might this study change your practice? Policy? Education? Research?

10. Who are the constituencies for the findings, and how they might be engaged in interpreting or using the findings?

11. What are the next steps in interpreting or applying the findings?

12. What researchable questions remain?

\section{References}

1. Stange KC, Miller WL, McLellan LA, et al. Annals Journal Club: It's time to get RADICAL. Ann Fam Med. 2006;4(3):196-197. http:// AnnFamMed.org/cgi/content/full/4/3/196. 